\title{
HUBUNGAN PENGETAHUAN, KUALITAS INTERAKSI, DUKUNGAN \\ KELUARGA, DAN SIKAP DENGAN KEPATUHAN MENGKONSUMSI \\ OBAT PADA PENDERITA ISPA DI PUSKESMAS NGAGLIK I SLEMAN
}

\author{
I Wayan Sudarta ${ }^{1}$, Lades ${ }^{2}$ \\ $\left({ }^{1,2}\right)$ STIKES Bethesda Yakkum Jln. Johar Nurhadi No.6 Yogyakarta 524565 \\ Email: wayantanaya@gmail.com
}

\begin{abstract}
ABSTRAK
Latar belakang : Kesehatan merupakan faktor penting dalam kehidupan. Lingkungan dan pola hidup masyarakat yang kurang sehat membuat masyarakat rentan terhadap penyakit, salah satunya ISPA. Dalam meminimalkan komplikasi dari ISPA diperlukan Pengetahuan, Kualitas Interaksi, Dukungan Keluarga, dan Sikap sehingga pasien patuh menjalani pengobatannya. Tujuan penelitian : Penelitian ini bertujuan untuk mengetahui hubungan Pengetahuan, Kualitas Interaksi, Dukungan Keluarga, dan Sikap dengan kepatuhan mengkonsumsi obat pada penderita ISPA di Puskesmas Ngaglik I Sleman Februari 2017. Metode penelitian : Desain penelitian ini adalah correlational dengan pendekatan cross sectional dilakukan di Puskesmas Ngaglik I Sleman tanggal 27 Februari-05 Maret 2017. Jumlah sampel ditentukan menggunakan rumus Slovin dan pengambilan sampel menggunakan Accidental Sampling sehingga mendapatkan 81 responden. Alat ukur menggunakan kuisioner. Hasil penelitian : Analisis bivariate dengan uji Spearman Rank dan anilasa multivariate menggunakan analisis Regresi Logistic Ordinal menunjukkan kualitas interaksi mempunyai peluang dan pegaruh paling tinggi terhadap kepatuhan minum obat dengan nilai signifikasi sebesar 0,01. Kesimpulan : Terdapat hubungan secara bersama-sama antara pengetahuan, kualitas interaksi, dukungan keluarga, dan sikap dengan kepatuhan mengkonsumsi obat ISPA di puskesmas Ngaglik I Sleman. Saran : Diharapkan peneliti selanjutnya dapat meneliti tentang peranan tenaga kesehatan dengan tingkat kepatuhan pasien mengkonsumsi obat ISPA.
\end{abstract}

Kata kunci : pengetahuan, kualitas interaksi, dukungan keluarga, sikap, kepatuhan mengkonsumsi obat, ISPA

ABSTRACT

Background: Health is an important factor in life. Environment and behavior of human society which are unhealthy make society suspectible from diseases, one of them is ISPA. To minimize the complication of ISPA, knowledge, quality of interaction, family support, and attitude is needed so that the can comply in medical treatment process. Purpose : To know the relationship between knowledge, quality of interaction, family support, and attitude with medication adherence of with ISPA in Puskesmas Ngaglik I, Sleman in February 2017. Methodology: It was a correlational research with cross sectional approach. This research was conducted at Puskesmas Ngaglik I Sleman on February ${ }^{27 t}$-March $5^{\text {th }}$, 2017. The number of sample was determined by using Slovin's formula and sampling using accidental sampling resulted 81 respondents. The instrument was questionnaire. Result : Bivariate analysis by Spearman Rank test and multivariate analysis using Ordinal Logistic Regression show quality of interaction has the opportunity and the highest impact on medication adherence with significant value 0,01. Conclusions: There is a relationship between knowledge, quality of interaction, family support, and attitude with medication adherence of with ISPA in Puskesmas Ngaglik I Sleman. Suggestion: It is expected that future researchers are able to examine the role of health personel with compliance level of consuming ISPA medication.

Keywords : Knowledge, quality of interaction, family support, attitude, medication adherence, ISPA 


\section{PENDAHULUAN}

Kesehatan sangat penting karena ketika kesehatan terjaga tubuh dapat bekerja lebih baik. Pola hidup yang tidak sehat seperti merokok serta lingkungan yang kurang bersih dapat menyebabkan kondisi sakit pada seseorang, salah satu masalah yang timbul adalah penyakit infeksi saluran pernapasan akut (ISPA). ISPA adalah radang akut pada pernapasan atas atau bawah, biasanya menular, yang dapat menimbulkan berbagai penyakit tanpa gejala atau infeksi ringan sampai penyakit yang parah dan mematikan (WHO 2007). Menurut WHO (2008) ISPA di India 43 juta, China 21 juta, Pakistan 10 juta, dan ISPA merupakan salah satu penyebab utama kunjungan pasien di Puskesmas (40$60 \%$ ). Tingginya prevalensi ISPA disebabkan karena ketidakpatuhan pada program terapi, 25\% menyangkut ketidakpatuhan pasien dalam pengobatan. Ketidakpatuhan pasien ISPA dalam mengkonsumsi obat ISPA dapat menyebabkan komplikasi seperti sinus paranasal, penutupan tuba eustachi, empiema, meningitis, dan bronkopneumonia serta berlanjut pada kematian karena adanya sepsis yang menular.

Hasil studi pendahuluan di Puskesmas Ngaglik I Sleman mendapatkan hasil 102 penderita ISPA usia $>17$ tahun. Hasil yang diperoleh setelah melakukan wawancara dengan 15 pasien ISPA yang berobat ke puskesmas yaitu 9 pasien mengatakan tidak rutin mengkonsumsi obat dengan alasan minum obat ketika gejala dan sakit tambah parah, 10 pasien mengatakan keluarga jarang mengingatkan untuk minum obat dan 5 pasien mengatakan informasi dari perawat kurang jelas dan kurang tahu akan program pengobatannya.

\section{METODE PENELITIAN}

Penelitian ini merupakan penelitian correlation dengan pendekatan cross sectional. Dilakukan di Puskesmas Ngaglik I Sleman Februari 2017. Populasi sebanyak 102 orang dan sampel sebanyak 81 responden diperoleh dengan rumus Slovin dan Accidental Sampling. Alat ukur menggunakan kuesioner.

\section{HASIL PENELITIAN}

1. Karakteristik Responden Berdasarkan Usia, Tingkat Pendidikan, Dan Jenis Kelamin Tabel 1.

Distribusi Frekuensi Responden Berdasarkan Usia, Tingkat pendidikan, dan Jenis Kelamin di Puskesmas Ngaglik I Sleman Februari 2017

\begin{tabular}{lcc}
\hline \multicolumn{1}{c}{ Usia } & Frekuensi & $\mathbf{\%}$ \\
\hline$<20$ tahun & 16 & 19.8 \\
\hline $21-30$ tahun & 12 & 14.8 \\
\hline $31-40$ tahun & 16 & 19.8 \\
\hline $41-50$ tahun & 31 & 38.3 \\
\hline $61-70$ tahun & 1 & 1.2 \\
\hline$>70$ tahun & 5 & 6.2 \\
\hline \multicolumn{1}{c}{ Jumlah } & 81 & 100.0 \\
\hline
\end{tabular}




\begin{tabular}{lcc}
\hline \multicolumn{1}{c}{ Tingkat Pendidikan } & Frekuensi & $\mathbf{\%}$ \\
\hline Tidak sekolah & 11 & 13.6 \\
\hline SD & 15 & 18.5 \\
\hline SMP & 18 & 22.2 \\
\hline SMA & 31 & 38.3 \\
\hline Perguruan tinggi & 6 & 7.4 \\
\hline \multicolumn{1}{c}{ Jumlah } & 81 & 100.0 \\
\hline \multicolumn{1}{c}{ Jenis Kelamin } & Frekuensi & $\mathbf{\%}$ \\
\hline Laki-laki & 53 & 65.4 \\
\hline Perempuan & 28 & 34.6 \\
\hline \multicolumn{1}{c}{ Jumlah } & 81 & 100.0 \\
\hline
\end{tabular}

Sumber: Primer terolah 2017

2. Deskripsi Variabel Lama Mengkonsumsi Obat

Tabel 2.

Deskripsi Variabel Responden Lama Mengkonsumsi Obat Di Puskesmas Ngaglik I Sleman Februari 2017

\begin{tabular}{|c|c|c|}
\hline Lama Mengkonsumsi Obat ISPA & Frekuensi & $\%$ \\
\hline$<7$ hari & 20 & 24.7 \\
\hline 7-14 hari & 25 & 30.9 \\
\hline 15-21 hari & 23 & 28.4 \\
\hline 22-28 hari & 5 & 6.2 \\
\hline$>28$ hari & 8 & 9.9 \\
\hline Jumlah & 81 & 100.0 \\
\hline
\end{tabular}

Sumber: Primer terolah 2017

3. Pengetahuan

Tabel 3.

Distribusi Frekuensi Responden Berdasarkan Tingkat Pengetahuan Di Puskesmas Ngaglik I Sleman Februari 2017

\begin{tabular}{|c|c|c|}
\hline Kategori Pengetahuan & Frekuensi & $\%$ \\
\hline Tinggi & 49 & 60.5 \\
\hline Sedang & 24 & 29.6 \\
\hline Rendah & 8 & 9.9 \\
\hline Jumlah & 81 & 100.0 \\
\hline
\end{tabular}

Sumber: Primer terolah 2017

4. Kualitas Interaksi

Tabel 4.

Distribusi Frekuensi Responden Berdasarkan Kualitas Interaksi di Puskesmas Ngaglik I Sleman Februari 2017

\begin{tabular}{|c|c|c|}
\hline $\begin{array}{c}\text { Kategori Kualitas } \\
\text { Interaksi }\end{array}$ & Frekuensi & $\%$ \\
\hline Baik & 37 & 45.7 \\
\hline Cukup & 20 & 24.7 \\
\hline Kurang & 24 & 29.6 \\
\hline Jumlah & 81 & 100.0 \\
\hline
\end{tabular}

Sumber: Primer terolah 2017 
5. Dukungan Keluarga

Tabel 5.

Distribusi Frekuensi Responden Berdasarkan Dukungan Keluarga Di Puskesmas Ngaglik I Sleman Februari 2017

\begin{tabular}{|c|c|c|}
\hline $\begin{array}{c}\text { Kategori Dukungan } \\
\text { Keluarga }\end{array}$ & Frekuensi & $\%$ \\
\hline Tinggi & 34 & 42.0 \\
\hline Sedang & 20 & 24.7 \\
\hline Rendah & 27 & 33.3 \\
\hline Jumlah & 81 & 100.0 \\
\hline
\end{tabular}

Sumber: Primer terolah 2017

6. Sikap

Tabel 6.

Distribusi Frekuensi Responden Berdasarkan Sikap Di Puskesmas Ngaglik I

Sleman Februari 2017

\begin{tabular}{lcc}
\hline \multicolumn{1}{c}{ Kategori Sikap } & Frekuensi & \% \\
\hline Baik & 34 & 42.0 \\
\hline Cukup & 23 & 28.4 \\
\hline Kurang & 24 & 29.6 \\
\hline \multicolumn{1}{c}{ Jumlah } & 81 & 100.0 \\
\hline
\end{tabular}

Sumber: Primer terolah 2017

7. Kepatuhan Mengkonsumsi Obat

Tabel 7.

Distribusi Frekuensi Responden Berdasarkan Kepatuhan Mengkonsumsi Obat di Puskesmas Ngaglik I Sleman Februari 2017

\begin{tabular}{|c|c|c|}
\hline $\begin{array}{l}\text { Kategori Kepatuhan } \\
\text { Mengkonsumsi Obat }\end{array}$ & Frekuensi & $\%$ \\
\hline Tinggi & 41 & 50.6 \\
\hline Sedang & 20 & 24.7 \\
\hline Rendah & 20 & 24.7 \\
\hline Jumlah & 81 & 100.0 \\
\hline
\end{tabular}

Sumber: Primer terolah 2017

8. Hubungan Pengetahuan dengan kepatuhan mengkonsumsi obat Tabel 8.

Hubungan Pengetahuan Dengan Kepatuhan Mengkonsumsi Obat Pada Penderita ISPA Di Puskesmas Ngaglik I Sleman Februari 2017

\begin{tabular}{|c|c|c|c|c|c|c|}
\hline Pengetahuan & & & & & Spearn & n Rank \\
\hline $\begin{array}{l}\text { Kepatuhan } \\
\text { minum obat }\end{array}$ & Tinggi & Sedang & Rendah & Jumlah & $\begin{array}{c}\text { Signifi- } \\
\text { cant }\end{array}$ & $\begin{array}{c}\text { Correlat } \\
\text { ion }\end{array}$ \\
\hline Tinggi & 34 & 5 & 2 & 41 & \multirow{4}{*}{0,00} & \multirow{4}{*}{0,405} \\
\hline Sedang & 7 & 9 & 4 & 20 & & \\
\hline Rendah & 8 & 10 & 2 & 20 & & \\
\hline Jumlah & 49 & 24 & 8 & 81 & & \\
\hline
\end{tabular}

Sumber: Primer terolah 2017 
9. Hubungan Kualitas Interaksi dengan Kepatuhan Mengkonsumsi Obat

Tabel 9.

Hubungan Kualitas Interaksi Dengan Kepatuhan Mengkonsumsi Obat Pada

Penderita ISPA Di Puskesmas Ngaglik I Sleman Februari 2017

\begin{tabular}{|c|c|c|c|c|c|c|}
\hline $\begin{array}{c}\text { Kualitas } \\
\text { interaksi }\end{array}$ & \multirow{2}{*}{ Tinggi } & \multirow{2}{*}{ Sedang } & \multirow{2}{*}{ Rendah } & \multirow{2}{*}{ Jumlah } & \multicolumn{2}{|c|}{ Spearman Rank } \\
\hline $\begin{array}{l}\text { Kepatuhan } \\
\text { minum obat }\end{array}$ & & & & & $\begin{array}{l}\text { Signifi- } \\
\text { cant }\end{array}$ & $\begin{array}{c}\text { Correlat } \\
\text { ion }\end{array}$ \\
\hline Tinggi & 37 & 0 & 4 & 41 & \multirow{4}{*}{0,00} & \multirow{4}{*}{0,868} \\
\hline Sedang & 0 & 20 & 0 & 20 & & \\
\hline Rendah & 0 & 0 & 20 & 20 & & \\
\hline Jumlah & 37 & 20 & 24 & 81 & & \\
\hline
\end{tabular}

Sumber: Primer terolah 2017

10. Hubugan Dukungan keluarga dengan Kepatuhan Mengkonsumsi Obat

Tabel 10.

Hubungan Dukungan Keluarga Dengan Kepatuhan Mengkonsumsi Obat Pada Penderita ISPA Di Puskesmas Ngaglik I Sleman Februari 2017

\begin{tabular}{|c|c|c|c|c|c|c|}
\hline $\begin{array}{c}\text { Dukungan } \\
\text { keluarga }\end{array}$ & \multirow{2}{*}{ Tinggi } & \multirow{2}{*}{ Sedang } & \multirow{2}{*}{ Rendah } & \multirow{2}{*}{ Jumlah } & \multicolumn{2}{|c|}{ Spearman Rank } \\
\hline $\begin{array}{l}\text { Kepatuhan } \\
\text { minum obat }\end{array}$ & & & & & $\begin{array}{l}\text { Signifi- } \\
\text { cant }\end{array}$ & $\begin{array}{c}\text { Correl } \\
\text { ation }\end{array}$ \\
\hline Tinggi & 34 & 0 & 7 & 41 & 0,00 & 0,775 \\
\hline Sedang & 0 & 20 & 0 & 20 & & \\
\hline Rendah & 0 & 0 & 20 & 20 & & \\
\hline Jumlah & 34 & 20 & 27 & 81 & & \\
\hline
\end{tabular}

Sumber: Primer terolah 2017

11. Hubungan Sikap dengan Kepatuhan Mengkonsumsi Obat

Tabel 11.

Hubungan Sikap Dengan Kepatuhan Mengkonsumsi Obat Pada Penderita ISPA Di Puskesmas Ngaglik I Sleman Februari 2017

\begin{tabular}{|c|c|c|c|c|c|c|}
\hline Sikap & & & & & Spearm & Rank \\
\hline $\begin{array}{l}\text { Kepatuhan } \\
\text { minum obat }\end{array}$ & & & 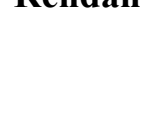 & somian & $\begin{array}{l}\text { Signifi- } \\
\text { cant }\end{array}$ & $\begin{array}{c}\text { Correl } \\
\text { ation }\end{array}$ \\
\hline Tinggi & 34 & 3 & 4 & 41 & \multirow{4}{*}{0,00} & \multirow{4}{*}{0,837} \\
\hline Sedang & 0 & 20 & 0 & 20 & & \\
\hline Rendah & 0 & 0 & 20 & 20 & & \\
\hline Jumlah & 34 & 23 & 24 & 81 & & \\
\hline
\end{tabular}

Sumber: Primer terolah 2017 
12. Hubungan Pengetahuan, Kualitas Interaksi, Dukungan Keluarga, dan Sikap dengan Kepatuhan Mengkonsumsi Obat

Tabel 12.

Hubungan Pengetahuan, Kualitas Interaksi, Dukungan Keluarga, Dan Sikap

Dengan Kepatuhan Mengkonsumsi Obat Pada Penderita ISPA

Di Puskesmas Ngaglik I Sleman Februari 2017

\begin{tabular}{lcccccccc}
\hline $\begin{array}{c}\text { Independent } \\
\text { variabel }\end{array}$ & Estimate & $\begin{array}{c}\text { Std. } \\
\text { Error }\end{array}$ & Wald & Df & Sig. & & \multicolumn{3}{c}{$\begin{array}{c}\text { 95\% } \\
\text { Confidence } \\
\text { Interval }\end{array}$} \\
\hline Pengetahuan & 1.283 & .651 & 3.882 & 1 & .049 & .007 & 2.560 \\
Bound & $\begin{array}{c}\text { Upper } \\
\text { Bound }\end{array}$ \\
\hline Kualitas Interaksi & 2.475 & .726 & 11.638 & 1 & .001 & 1.053 & 3.897 \\
\hline $\begin{array}{l}\text { Dukungan } \\
\text { Keluarga }\end{array}$ & 1.911 & .717 & 7.112 & 1 & .008 & .507 & 3.316 \\
\hline Sikap & 2.109 & .739 & 8.133 & 1 & .004 & .660 & 3.558 \\
\hline
\end{tabular}

Sumber: Primer terolah 2017

\section{PEMBAHASAN}

1. Karakteristik berdasarkan usia

Usia responden yang menderita ISPA terbanyak yaitu usia 41-50 tahun. Pada usia 40 tahun ke atas mempunyai resiko tinggi menderita penyakit ISPA karena terjadi gangguan paru-paru dimana kualitas paru-paru mulai memburuk dan disertai dengan melemahnya imunitas.

2. Karakteristik berdasarkan tingkat pendidikan

Pendidikan responden yang terbanyak adalah tingkat pendidikan SMA sebanyak 31 responden (38,3\%). Pendidikan tidak berpengaruh terhadap kejadian ISPA, tergantung dari seberapa sering masyarakat terpapar dengan pendidikan kesehatan tentang ISPA.

3. Karakteristik berdasarkan jenis kelamin Penderita ISPA lebih banyak terjadi pada laki-laki yaitu sebanyak 53 responden $(65,4 \%)$. Salah satu faktor resiko ISPA adalah jenis kelamin dimana laki-laki lebih banyak aktivitas sehingg peluang terpapar oleh agent lebih banyak.

4. Karakteristik responden berdasarkan lama mengkonsumsi obat

Responden terbanyak dalam mengkonsumsi obat adalah dalam rentang 7-14 hari yaitu 25 responden (30,9\%). Subjek yang telah mengkonsumsi obat ISPA kurang dari satu minggu yaitu sesuai rentang waktu yang dianjurkan Petugas kesehatan mempunyai kepatuhan lebih tinggi daripada yang mengkonsumsi obat ISPA lebih dari tujuh hari.

5. Pengetahuan

Pengetahuan yang rendah pada responden ada sebanyak 39,5\%. Tingkat pengetahuan seseorang berpengaruh dalam memberikan respon terhadap sesuatu yang datang dari luar, pengetahuan mempengaruhi ketaatan seseorang terhadap peraturan atau standar yang berlaku. 
6. Kualitas Interaksi

Kualitas interaksi kurang sebanyak $54,3 \%$. Kualitas interaksi yang disampaikan petugas kesehatan kepada pasien akan mempengaruhi hasil evaluasi klien.

7. Dukungan Keluarga

Dukungan keluarga yang kurang ada sebanyak 58\%. Dukungan keluarga dapat menjadi sangat berpengaruh dalam menentukan nilai keyakinan dan nilai kesehatan individu serta dapat menentukan program kesehatan yang mereka terima.

8. Sikap

Pasien yang kurang untuk mengkonsumsi obat ISPA ada sebanyak 58\%. Sikap menunjang proses sembuh atau tidaknya pasien dalam pengobatannya.

9. Kepatuhan mengkonsumsi obat

Ketidakpatuhan pasien mengkonsumsi obat ISPA ada sebanyak 49,4\%. Tingkat kepatuhan pasien dalam mengkonsumsi obat dapat dipengaruhi oleh faktor dalam diri pasien sendiri seperti lupa minum obat.

10. Hubungan pengetahuan dengan kepatuan mengkonsumsi obat

Hasil uji Spearman Rank p-value $=0,00$ $(p$-value $<\alpha)$ maka dapat disimpulkan ada hubungan dengan keeratan sedang. Pengetahuan mempengaruhi sesorang dalam hal kepatuhan mengkonsumsi obat.

11. Hubungan kualitas interaksi dengan kepatuhan mengkonsumsi obat

Hasil uji Spearman Rank p-value $=0,00$ $(p$-value $<\alpha)$ maka dapat disimpulkan ada hubungan dengan keeratan sangat tinggi. Kualitas interaksi yang baik antara petugas kesehatan dengan pasien mempunyai pengaruh terhadap kepatuhan dalam mengkonsumsi obat.

12. Hubungan dukungan keluarga dengan kepatuhan mengkonsumsi obat

Hasil uji Spearman Rank p-value $=0,00$ $(p$-value $<\alpha)$ maka dapat disimpulkan ada hubungan dengan keeratan tinggi. Tingginya kepatuhan mengkonsumsi obat dapat disebabkan oleh dukungan keluarga yang adekuat.

13. Hubungan sikap dengan kepatuhan mengkonsumsi obat

Hasil uji Spearman Rank p-value $=0,00$ $(p$-value $<\alpha)$ maka dapat disimpulkan ada hubungan dengan keeratan sangat tinggi. Sikap sangat mempengaruhi kepatuhan seseorang dalam minum obat.

14. Hubungan pengetahuan, kualitas interaksi, dukungan keluarga, dan sikap dengan kepatuhan mengkonsumsi obat. Hasil uji regresi logistic ordinal diketahui bahwa yang paling berhubungan dengan kepatuhan mengkonsumsi obat ISPA adalah kualitas interaksi dengan nilai p-value/signifikasi 0.01 . Kualitas interaksi yang baik mempengaruhi responden dalam menentukan nilai keyakinan terhadap pengobatan yang diterimannya.

\section{KESIMPULAN}

Hasil penelitian hubungan pengetahuan, kualitas interaksi, dukungan keluarga, sikap dengan kepatuhan mengkonsumsi obat pada penderita ISPA di Puskesmas Ngaglik I Sleman Februari 2017 adalah sebagai berikut : 
a. Pengetahuan responden yang kurang tentang ISPA perlu diberikan penyuluhan tentang ISPA, kualitas interaksi antar Petugas kesehatan dengan pasien perlu ditingkatkan supaya informasi yang diterima pasien jelas, tugas dan fungsi keluarga di masyarakat harus benarbenar diterapkan supaya sikap pasien dalam mengkonsumsi obat ISPA tinggi dan kekambuhan untuk penyakit ISPA akan berkurang bahkan menghilang.

b. Variabel yang paling berhubungan dengan kepatuhan mengkonsumsi obat pada penderita ISPA adalah kualitas interaksi karena mempunyai nilai keeratan paling kecil dengan nilai sig $0,01<0,05$.

\section{SARAN}

1. Keluarga penderita ISPA

Harapannya bagi keluarga dapat memahami dan menerapkan lima tugas keluarga. Memberikan saran atau nasihat kepada penderita ISPA tentang kondisi yang dapat memperberat atau meringankan penyakitnya, memberikan perhatian dan mendengarkan keluhan penderita ISPA.

2. Puskesmas Ngaglik I Sleman

Puskesmas dapatmemberikan penyuluhan atau pendidikan kesehatan tentang ISPA supaya angka kejadian ISPA menurun, kualitas interaksi yang disampaikan Petugas kesehatan harus bermutu dan baik supaya pasien mengerti apa yang disampaikan karena akan mempengaruhi kepatuhan pasien dalam pengobatannya, dan sosialisasi kepada keluarga penderita ISPA untuk memberikan dukungan kepada penderita ISPA.
3. Peneliti selanjutnya

Bagi peneliti selanjutnya yang tertarik meneliti tingkat kepatuhan mengkonsumsi obat diharapkan dapat meneliti tentang peran dan tugas keluarga terhadap kepatuhan mengkonsumsi obat ISPA, peranan tenaga kesehatan dengan kepatuhan pasien mengkonsumsi obat, pengaruh pengawasan minum obat pada penderita ISPA, dan pendidikan kesehatan tentang ISPA.

\section{DAFTAR PUSTAKA}

Asti, Tri. (2008). Kepatuhan Pasien : Faktor Penting Dalam Keberhasilan Terapi. Jakarta : BPOM

Boyoh, Marshal Edwin. (2015). Hubungan Pengetahuan Dengan Kepatuhan Minum Obat Pada Pasien DM 2 Di Poliklinik Endokrin Rumah Sakit Prof. DR. R. D. Manado : Kandou.

Brady, M. K. \& Cronin, J. J. (2009). Custumer Orientatio : Effects On Customer Service Perceptions and Outcomes Behaviors Journal Of Service Research. Diakses pada tanggal 23 November dari hhtp:// portal.koperties.or.id.

Cipolle, R.J., Strand, L.M., dan Morley, P.C. (2008). Pharmaceutical Care Practice The Mc Graw Hills Companies. Diakses pada 22 November 2016 dari http:// www.eprints.ums.ac.id

Fitria Halimn. (2012). Hubungan Faktor Lingkungan Fisik Dengan Kejadian Infeksi Saluran Pernapasan Akut Pada Pekerja Di Industri Mebel Dukuh Tukrejo, Desa Bondo, Kecematan Langsari, Kabupaten Jepara, Propinsi Jawa Tengah. Depok : Universitas Indonesia. 
Hartini, Sri, dkk. (2011). Pengaruh Pendidikan Kesehatan Tentang Penatalaksanaan ISPA Terhadap Pengetahuan dan Keterampilan Ibu Merawat Balita Di Rumah. Semarang: Telogorejo

Junita, Friska. (2012). Hubungan Pengetahuan dan Sikap Dengan Kepatuhan Minum Obat Anti Tuberculosis Pada Pasien Tuberculosis Paru Di Puskesmas Kecematan Jatinegara. Bekasi : Sekolah Tinggi Ilmu Kesehatan Medistra Indonesia.

Lailatushifah, Siti Noor Fatimah. (2009). Kepatuhan Pasien yang Menderita Penyakit Kronis Dalam Mengkonsumsi Obat Harian. Yogyakarta: Fakultas Psikologi Universitas mercu Buana Yogyakarta.

Ngastiyah. (2008). Perawatan Anak Sakit Edisi 2. Jakarta : EGC.

Niven. (2012). Psikologi Kesehatan : Pengantar Untuk Perawat dan Profesi Kesehatan Lain. Jakarta : EGC.

Prayogo, Akhmad Hudan Eka. (2013). Faktorfaktor Yang Mempengaruhi Kepatuhan Minum Obat Anti Tuberculosis Pada Pasien TB Paru Di Puskesmas Pamulang Kota Tanggerang Selatan Propinsi Banten Periode. Jakarta : Universitas Islam Negri Syarif Hidayatullah.

Smantunmkul, Chayanee. (2014). Tingkat Kepatuhan Penggunaan Obat Antihipertensi pada Pasien Hipertensi di Instalasi Rawat Jalan Rumah Sakit Surakarta pada Tahun 2014. Surakarta : Universitas Muhammadiyah Surakarta.

WHO. (2007). Pedoman Pencegahan dan Pengendalian Infeksi Saluran Pernapasan Akut (ISPA) Yang
Cenderung Menjadi Epidemi dan Pandemi di Fasilitas Pelayanan Kesehatan. Janewa : WHO.

WHO. (2008). Pedoman Pencegahan dan Pengendalian Infeksi Saluran Pernapasan Akut (ISPA) Yang Cenderung Menjadi Epidemi dan Pandemi di Fasilitas Pelayanan Kesehatan. Janewa : WHO.

Yusuf, Achamad Nur \& Sulistyorini, lilis. (2008). Hubungan Sanitasi Rumah Secara Fisik Dengan Kejadian ISPA Pada Balita. Jurnal Kesehatan Lingkungan. 